\title{
Editorial
}

\section{"PERSPECTIVA DO TEMPO PARA VISUALIZAÇAO DA ENFERMAGEM"}

Foi realizado o $\mathrm{XXX}$ Congresso Brasileiro de Enfermagem na Grande Região Norte: em Belém do Pará. Este fato é motivo de reflexões. Justamente transoorreram sete anos desde 1971, ano em que se realizou, em Manaus, o XXIII Congresso Brasileiro de Enfermagem.

Nesse espaço de sete anos, muitos teriam sido os acontecimentos marcantes, nos campos da enfermagem, que se ligam principalmente a seus aspectos de: 1) Assistência de enfermagem para o público, e ensino, tanto de graduação como de pós-graduação de enfermagem; 2) As instituições do trabalho: Conselhos Federal e Regionais de Enfermagem, empregas; grupos sociais; ética profissional. Vejamos.

Os sete anos medeando entre estes dois Congressas foram notáveis.

\section{"ASSISTENCIA E ENSINO DE ENFERMAGEM"}

Não conhecemos com a clareza que a pesquisa mostraria as atuais condiçōes da assistência de enfermagem, no País. $O$ último levantamento sobre esse assunto referives aos anos de 1956 a 1957. Uma coisa é certa: as enfermoiras (os) são em número insuficiente. São escassos os quantitativos, para fazer-se face à elaboração de programas em seguida aos planos de saúde. Entretanto um fato de Brande significaçāo ocorreu: o Ministério da Educação e Cultura mostrou-se impressionado com esse necessidade numérica de enfermeiros, segundo the teria sido descrito pelos Ministério da Saúde e da Pre vidência e Alssistência Social. Desse modo têm surrgidos de 1975 até o presente, providências do Departamento de Assuntos Universitários do Ministério da Educação e Cultura para aumentur o número do Cursos a do vagas no ensino de enfermagem e obstetrícia, no País. Tal esforço continua cada vez mais vigoroso; no devido tempo, seus resultados pasitivos deverão contribuir para melhorar as serviços de saúde em geral.

Tem havido outros fatos novos: em 1972 iniciou-se o Curso de Mestrado em Enfermagem na Universidade Federal do Rio de Janeiro (Escola de Enfermagem Ana Néri), seguido de dois na Universidade de São Paulo, além de outros atualmente em início de funcionamento.

\section{"INSTITUIÇOESS DO TRABALHO"}

Data de abril de 1975 a instalação do primeiro Congresso Federal de Enfermagem, e data de outubro do mesmo ano a instalação dos primeiros 
Conselhos Regionais em cada Estado. Eles visam dar apoio e guia ético a todo pessoal que trabalha em enfermagem. Hoje graças ao Conselho Federal de Enfermagem já existe o código de Deontologia de Enfermagem que vigora desde 1976. Temos, ainda, em cada COREN para o Desenvolvimento Profissional do Pessoal de Enfermagem programa de cursos a serem ministrados.

Quanto a empregos, no País, continua a haver falta de providências a fim de criarem-se empregos para os técnicos de enfermagem. Terão que ha. ver empregos solicitados pelos setores que estão com as atividades a seren executađas; por exemplo, nos serviços de governos, os hospitais, ambulatórios e serviços oficiais de saúde pública terão que dar início aos expedientes sobre o asunto. $O$ que se deve obter são empregos regidos pela Consolidação das Leis do Trabalho.

Os grupos sociais na enfermagem, devem ser coesos; devemos estimular o maior número de coincidência de pontos de vista (consensos) entre os grupos das categorias de pessoal de enfermagem. Por exemplo, estamos todos de acordo com o nosso Código de Deontologila de Enfermagem aprovado pelo COFEN.

Nos serviços de saúde estamos reunidos em equipes que têm a cooperação como ideal comum.

Associam-se na $A B E n$ os enfermeiros e os técnicos de enfermagem; e na UNATE, os auxiliares de enfermagem. Também os técnicos, se o desejarem, podem se associar com os auxiliares de enfermagem. E generalizado o desejo de progredir: unimo-nos para podermos ter, comunitariamente, progresso próprio.

E bom que se divulgue que no Brasil temos conseguido um modo racional para apressar a valorização dos que trabalham. Refere-se ao seguinte. $E$ uma realidade a passagem de uma categoria de pessoal para outra categoria superior. Muitos auxiliares de enfermagem (e, mesmo os atendentes que estão em condições) se submetem à suplência profissionalizante para serem técnicos de enfermagem, bem como obtêm sua aprovação nos cursos regulares ou supletivos de $2 .^{\circ}$ grau. Não é fácil; porém muitos têm conseguido tal progresso.

Finalizando, os dois Congressos Brasileiros realizados na Região Norte, de 1971 e 1978, prestam-se a estudo de evidências do exercício e do ensino da enfermagem, bem como dos aspectos institucionais referidos, tanto dos enfermeiros quanto dos demais (técnicos e auxiliares) abrangidos nos serviçes de enfermagem, levandonos não só à constatação de progressos significativos como também às aspirações de ver resolvidos os obstáculos que surgem. Todos, coesos, apresentamo-nos a conseguir acelerar o desenvolvimento da enfermagem para um Brasil renovado.

(HGD) 